\title{
Radiography Versus Magnetic Resonance Imaging (MRI) in Juvenile Spondyloarthritis: Is the MR Image Everything?
}

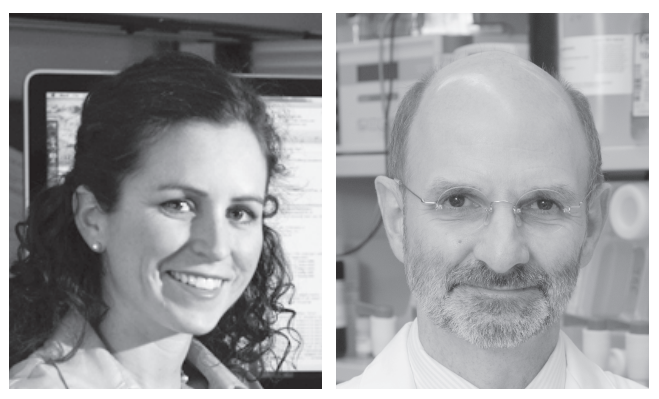

Spondyloarthritis $(\mathrm{SpA})$ represents a group of related rheumatic diseases that includes ankylosing spondylitis (AS), psoriatic arthritis (PsA), arthritis associated with inflammatory bowel disease, and reactive arthritis, with $10-20 \%$ of patients developing their first symptoms during childhood. Juvenile SpA more often begins with peripheral and root joint arthritis and enthesitis than with back pain, the most common presenting feature in adults, even when the eventual outcome is ankylosing spondylitis (AS) ${ }^{1}$. These differences have necessitated the adoption of age-specific SpA classification criteria where the most common forms of juvenile SpA are encompassed by enthesitis-related arthritis (ERA), psoriatic arthritis (PsA), and undifferentiated arthritis $^{2}$. In adults, SpA classification has moved from distinguishing undifferentiated and differentiated disease $\mathrm{e}^{3,4}$ toward criteria that identify patients with back pain who have "axial SpA" (axSpA) versus those with peripheral manifestations only ${ }^{5}$. AxSpA is present if back pain is present for at least 3 months and is associated with evidence of sacroiliac involvement on imaging [radiographs or magnetic resonance imaging (MRI)], or when HLA-B27 and additional features of SpA are present ${ }^{6}$. Peripheral SpA requires arthritis, enthesitis, or dactylitis, and other features of $\mathrm{SpA}^{5}$. Although axSpA defines individuals who are more likely to develop AS, it is not yet clear what proportion of individuals will eventually fulfill the modified New York criteria. Nevertheless, identifying patients with $\mathrm{SpA}$ who have active sacroiliitis on MRI and/or early radiographic changes has important implications for treatment and potentially for changing the outcome of disease.

Age-dependent differences in the presentation and progression of $\mathrm{SpA}$ present unique challenges for pediatric (and adult) rheumatologists evaluating children suspected of having $\mathrm{SpA}$. There are currently no criteria to define axial disease in children, and the axSpA criteria are likely to be insensitive given the requirement for 3 months of back pain. In the absence of localizing symptoms such as back or buttock pain, or findings on physical examination, when should the sacroiliac joint be imaged? Further, what is the best imaging modality when sacroiliitis is suspected, and if present, should it influence the approach to treatment?

In this issue of The Journal, Jaremko, et al address another important question ${ }^{7}$ : When symptoms suggestive of sacroiliitis are present, what imaging modality — radiography or MRI - is most useful in establishing a diagnosis of SpA? They used a retrospective approach, identifying a cohort of children who had imaging of their sacroiliac joints by MRI and radiography for back or sacroiliac joint pain, for whom a clear final clinical diagnosis was reached. Back pain did not have to meet the definition of inflammatory back pain. Patients with juvenile SpA (JSpA) had a final diagnosis of ERA, PsA, or undifferentiated arthritis as defined by the International League of Associations for Rheumatology criteria, or arthritis associated with inflammatory bowel disease. Subjects eventually diagnosed with conditions other than JSpA served as controls, and included trauma, oligo-, or polyarticular juvenile idiopathic arthritis, mechanical back pain, spondylolisthesis, cystic fibrosis arthropathy, structural abnormalities, or fibromyalgia. Standard definitions for radiographic and MRI abnormalities from the adult $\mathrm{SpA}$ literature were used, and sensitivity, specificity, and likelihood ratios for each imaging modality were calculated using physician-determined JSpA diagnosis as the reference standard.

Several findings in this study are worth highlighting. First, there was a high frequency of abnormalities in the non-SpA control group, with sclerosis $(55 \%$ by radiography and $34 \%$ by MRI), erosion (20\% radiography/9\% MRI), and bone marrow edema ( $20 \%$ by MRI) being relatively common. Second, sclerosis, erosion, and joint space narrowing were identified more often by radiograph than MRI in both cases and controls. Third, the global impression from imaging indicative of JSpA as per the radiologist was not much different using radiographs versus

See Diagnosing JSpA with MRI, page 963

Personal non-commercial use only. The Journal of Rheumatology Copyright (C) 2014. All rights reserved. 
MRI. For example, the prevalence of positive global impression was $50 \%$ versus $54 \%$, and sensitivities for the detection of physician JSpA diagnosis were 0.50 and 0.54 for radiographs and MRI, respectively. The specificity of the global impression was also similar for radiographs and MRI (0.89 vs 0.94 , respectively). Finally, interrater agreement was fair to moderate for radiographic abnormalities, poor for joint space narrowing on MRI, fair for sclerosis on MRI, and moderate for bone marrow edema and erosions on MRI. Overall the results of this study support the superiority, albeit marginal, of MRI over radiographs for evaluation of sacroiliitis in children with back or sacroiliac pain and suspected SpA.

These results are somewhat surprising given that several studies have demonstrated greater superiority of MRI over radiographs for the detection of early sacroiliitis in adults ${ }^{8,9,10}$. Some of the reasons for the less impressive differences in this study may be the choice of individuals who had an indication for sacroiliac imaging as controls, as well as the use of a physician diagnosis of JSpA as a reference standard. Given the high prevalence of abnormalities in this control population, it will be important to evaluate normal healthy children with both imaging modalities. It is challenging to identify what is "abnormal," when the prevalence of what is defined as abnormal has not been established in children. In addition, evaluating the diagnostic utility of imaging modalities for sacroiliitis in physician-defined JSpA is a little confusing because axial arthritis is not required for a diagnosis of JSpA, and many children with JSpA will never develop axial disease.

As the authors are careful to point out, because this study focused on the sacroiliac joint in children with back or sacroiliac pain, there are limitations to applying these findings to other stages of JSpA. For example, while this work supports the use of MRI in establishing the presence of axSpA, radiographs remain the standard on which sacroiliac damage is graded in the modified New York criteria for AS. Despite limitations, this work provides important guidance for clinicians evaluating children with back pain and suspected SpA. Although the utility of gadolinium-enhanced MRI was not addressed by this study, the implication is that this contrast agent and its associated risks are not necessary in the evaluation of suspected sacroiliitis in children.

\section{PAMELA F. WEISS, MD,}

Division of Rheumatology,

Children's Hospital of Philadelphia,

Philadelphia, Pennsylvania;

ROBERT A. COLBERT, $\mathrm{MD}, \mathrm{PhD}$,

Pediatric Translational Research Branch,

National Institute of Arthritis and Musculoskeletal and Skin Diseases,

National Institutes of Health,

Bethesda, Maryland, USA.
Address correspondence to Dr. Colbert, NIH-NIAMS, 10-CRC, Hatfield Clinical Research Center, 1-5142 10 Center Dr., Bethesda, Maryland 20892-1102, USA. E-mail: colbertr@mail.nih.gov

\section{REFERENCES}

1. Riley MJ, Ansell BM, Bywaters EG. Radiological manifestations of ankylosing spondylitis according to age at onset. Ann Rheum Dis 1971;30:138-48.

2. Colbert RA. Classification of juvenile spondyloarthritis: Enthesitis-related arthritis and beyond. Nat Rev Rheumatol 2010;6:477-85.

3. Amor B, Dougados M, Mijiyawa M. Criteria of the classification of spondylarthropathies [French]. Rev Rhum Mal Osteoartic 1990;57:85-9.

4. Dougados M, van der Linden S, Juhlin R, Huitfeldt B, Amor B, Calin A, et al. The European Spondylarthropathy Study Group preliminary criteria for the classification of spondylarthropathy. Arthritis Rheum 1991;34:1218-27.

5. Rudwaleit M, van der Heijde D, Landewe R, Akkoc N, Brandt J, Chou CT, et al. The Assessment of SpondyloArthritis International Society classification criteria for peripheral spondyloarthritis and for spondyloarthritis in general. Ann Rheum Dis 2011;70:25-31.

6. Rudwaleit M, van der Heijde D, Landewe R, Listing J, Akkoc N, Brandt J, et al. The development of Assessment of SpondyloArthritis international Society classification criteria for axial spondyloarthritis (part II): validation and final selection. Ann Rheum Dis 2009;68:777-83.

7. Jaremko JL, Liu L, Winn NJ, Ellsworth JE, Lambert RG. Diagnostic utility of magnetic resonance imaging and radiography in juvenile spondyloarthritis: Evaluation of the sacroiliac joints in controls and affected subjects. J Rheumatol 2014;41:963-70.

8. Puhakka KB, Jurik AG, Egund N, Schiottz-Christensen B, Stengaard-Pedersen K, van Overeem Hansen G, et al. Imaging of sacroiliitis in early seronegative spondylarthropathy. Assessment of abnormalities by MR in comparison with radiography and CT. Acta Radiol 2003;44:218-29.

9. Blum U, Buitrago-Tellez C, Mundinger A, Krause T, Laubenberger $\mathrm{J}$, Vaith P, et al. Magnetic resonance imaging (MRI) for detection of active sacroiliitis - a prospective study comparing conventional radiography, scintigraphy, and contrast enhanced MRI. J Rheumatol 1996;23:2107-15.

10. Oostveen J, Prevo R, den Boer J, van de Laar M. Early detection of sacroiliitis on magnetic resonance imaging and subsequent development of sacroiliitis on plain radiography. A prospective, longitudinal study. J Rheumatol 1999;26:1953-8.

J Rheumatol 2014;41:832-3; doi:10.3899/jrheum.140212 